\title{
Research on the Stability Control Strategy of Four-Wheel Independent Driving Electric Vehicle
}

\author{
Bo Peng, Huanhuan Zhang, Peiteng Zhao \\ College of Automotive Engineering, Shanghai University of Engineering and Science, Shanghai, China \\ Email:pengbo1127@foxmail.com
}

How to cite this paper: Peng, B., Zhang, H.H. and Zhao, P.T. (2017) Research on the Stability Control Strategy of Four-Wheel Independent Driving Electric Vehicle. Engineering, 9, 338-350. https://doi.org/10.4236/eng.2017.93018

Received: February 15, 2017

Accepted: March 28, 2017

Published: March 31, 2017

Copyright (๑) 2017 by authors and Scientific Research Publishing Inc. This work is licensed under the Creative Commons Attribution International License (CC BY 4.0).

http://creativecommons.org/licenses/by/4.0/

\begin{abstract}
In order to research stability of four-wheel independent driving (4WID) electric vehicle, a torque allocation method based on the tire longitudinal forces optimization distribution is adopted. There are two layers in the controller, which includes the upper layer and the lower layer. In the upper layer, according to the demand of the longitudinal force, PID controller is set up to calculate the additional yaw moment created by yaw rate and side-slip angle. In the lower layer, the additional yaw moment is distributed properly to each wheel limited by several constraints. Carsim is used to build up the vehicle model and MATLAB/Simulink is used to build up the control model and both of them are used to simulate jointly. The result of simulation shows that a torque allocation method based on the tire longitudinal forces optimization distribution can ensure the stability of the vehicle.
\end{abstract}

\section{Keywords}

Independent Drive, Electric Vehicle, Torque Allocation, Vehicle Stability PID Control

\section{Introduction}

Four-wheel independent driving electric vehicle removes parts such as engines, clutches, gearboxes. Its structure is simpler than traditional vehicle. Because each wheel has a hub motor, it is more precise and convenient to control the torque on each wheel [1] [2] [3]. With the development of technology, consumers' expectations for vehicle safety are also increasing. Controlling the torque on each wheel to improve the stability of the vehicle has become increasingly valuable [4] [5] [6].

In the stability of 4WID electric vehicle research, there are four-wheel steering 
system and direct yaw moment control method to improve vehicle stability. However, the four-wheel steering system cannot meet the stability requirements under extreme driving condition, and the direct yaw moment control also has the accuracy problem [7]. Therefore, many researchers have focused on the use of optimized torque distribution to improve the stability of the vehicle. Yu et al. simulated the longitudinal force control assignment of the wheel drive electric vehicle, and show the effectiveness of the distribution control algorithm [8]. Ding et al. used the simple average distribution method that is one side increases the torque and the other side reduces the torque by the same amount. The control method does not take into account the vehicle's constraint condition and the different states, and cannot accurately control the vehicle [9]. Miao used the weighted least squares method to calculate the torque distribution [10]. The weighted least squares method has the advantages in calculating the speed and iterative accuracy, but there is no solution to the case where the yaw moment is large. This paper proposes a torque distribution strategy based on longitudinal force optimization, combined with the designed layered controller and tire constraints. This strategy optimizes the torque distribution and combines with the advantages of 4WID electric vehicle chassis to achieve the stability of the vehicle control. This paper simulates 4WID electric vehicle on a double lane change and slalom. The simulation results show that the proposed control strategy can improve vehicle stability.

\section{Control Strategy}

\subsection{Torque Distribution Control}

When the vehicle is running at high speed and suddenly turns, it will cause the yaw rate to be too large and cause the vehicle to be unstable. Comparing the accelerator pedal signal and the steering wheel signal actually entered with the ideal linear two-degree-of-freedom model, the strategy calculates the additional yaw moment required and allocated torque rationally to the hub motor and the brakes on the wheels to correct the excessive yaw moment.

According to [11], it can be seen that increasing the torque of the inner wheels of the 4WID electric vehicle and reducing the torque of the outer wheels can reduce the yaw moment of the vehicle. According to the Tang [12], in the traditional vehicle, the front wheel brake to correct the excessive yaw moment is most effective.

This paper combines the above two methods to design a control strategy. The strategy is divided into two stages. The first stage is reducing the torque on the motor on the outer wheel when the vehicle's yaw rate is too large and unstable. The second stage is braking the vehicle outside wheels when the torque on the outer wheels cannot guarantee the stability of the vehicle after the reduction of torque (The flow chart of control strategy is shown in Figure 1).

\subsection{Torque Distribution Control Structure}

The structure designed is showed in Figure 2, including drive torque controller, 


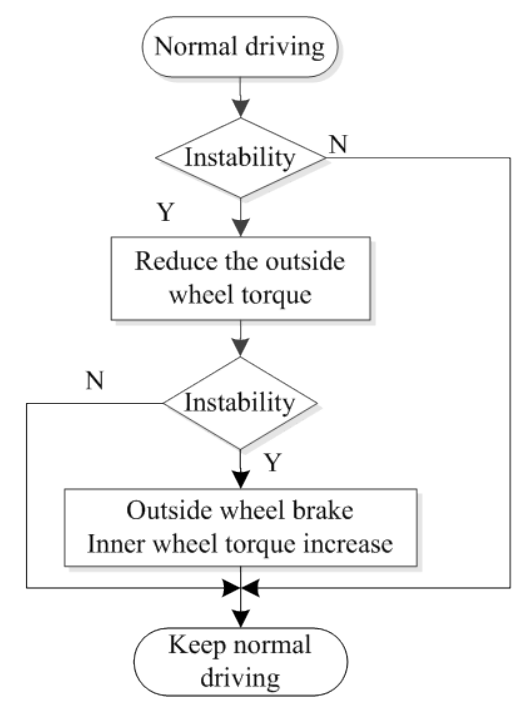

Figure 1. Flow chart of control strategy.

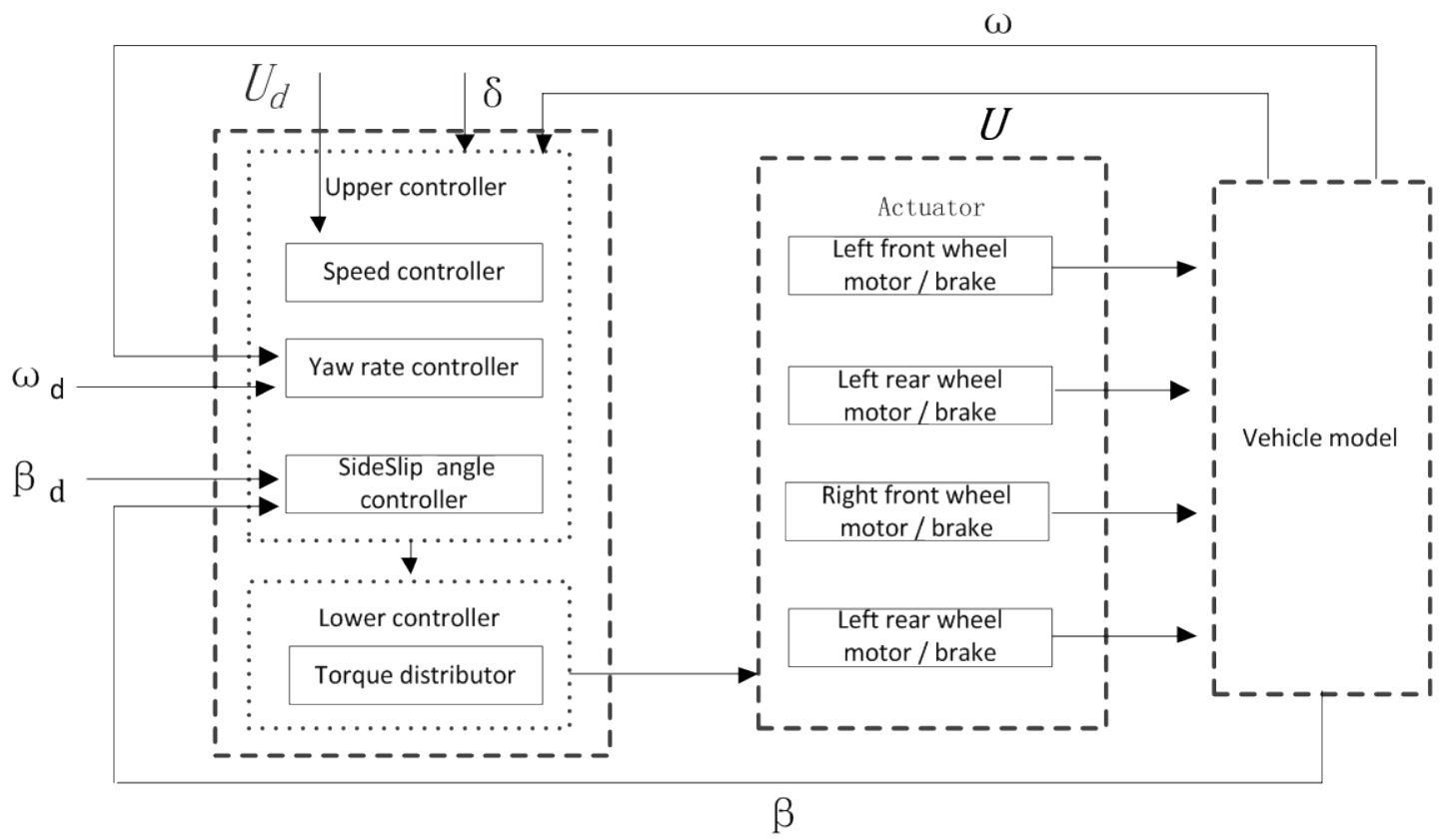

Figure 2. Torque distribution control structure.

actuator and vehicle model. The drive torque controller is divided into an upper controller and a lower controller. The upper controller includes a speed controller, a yaw velocity controller, and a sideslip angle controller. The lower controller is the torque distributor. The upper controller calculates the desired additional yaw moment according to the state of the vehicle input and passes the torque to the lower controller. The lower controller reasonably assigns the additional yaw moment transmitted by the upper controller to the actuator according to the constraints. In Figure 2, $\boldsymbol{u}_{\boldsymbol{d}}$ and $\boldsymbol{u}$ represent the target speed and actual speed of the vehicle respectively; $\omega_{d}$ and $\omega$ represent the ideal yaw rate and actual yaw rate of the vehicle respectively; $\beta_{d}$ and $\beta$ represent the ideal sideslip angle and the actual sideslip angle. 


\section{Controller}

\subsection{Speed Controller}

According to the speed controller provided in [13], the total torque $T_{Z}$ required for the vehicle is related to the front wheel angle $\delta$, which can be express as:

$$
T_{Z}=S \cdot\left(u_{d}-u\right)
$$

where $S$ is proportional coefficient.

Since $\delta<0$, the total torque is coordinated to the motor on each wheel. Since $\delta=0$, each wheel shares the motor torque of $1 / 4 T_{Z}$. Although the steering wheel has a large input in a short time and the speed of the vehicle is very high, but the front wheel angle is very small, this time can be considered the average torque distribution. In addition, because it is uniform speed, the difference between $u_{d}$ and $u$ is very small, then $T_{Z}$ is also very small.

\subsection{Yaw Moment Controller}

The linear two-degree-of-freedom model in [14] is showed in Figure 3. The equation of motion can be expressed as:

$$
\left\{\begin{array}{l}
m u(\dot{\beta}+\omega)=\left(C_{1}+C_{2}\right) \beta+\frac{1}{u}\left(a C_{1}-b C_{2}\right) \omega-C_{1} \delta \\
I_{Z} \dot{\omega}=\left(a C_{1}-b C_{2}\right) \beta+\frac{\left(a^{2} C_{1}+b^{2} C_{2}\right)}{u} \omega-a C_{1} \delta
\end{array}\right.
$$

where $C_{1}$ and $C_{2}$ are the lateral stiffness of the front and rear wheels; $a$ and $b$ are the distances from the vehicle center of mass to the front and rear axle wheelbase; $m$ is the vehicle mass; $I_{Z}$ is the moment of inertia of the vehicle around the $Z$ axis. The equation of motion is rewritten in the state equation form:

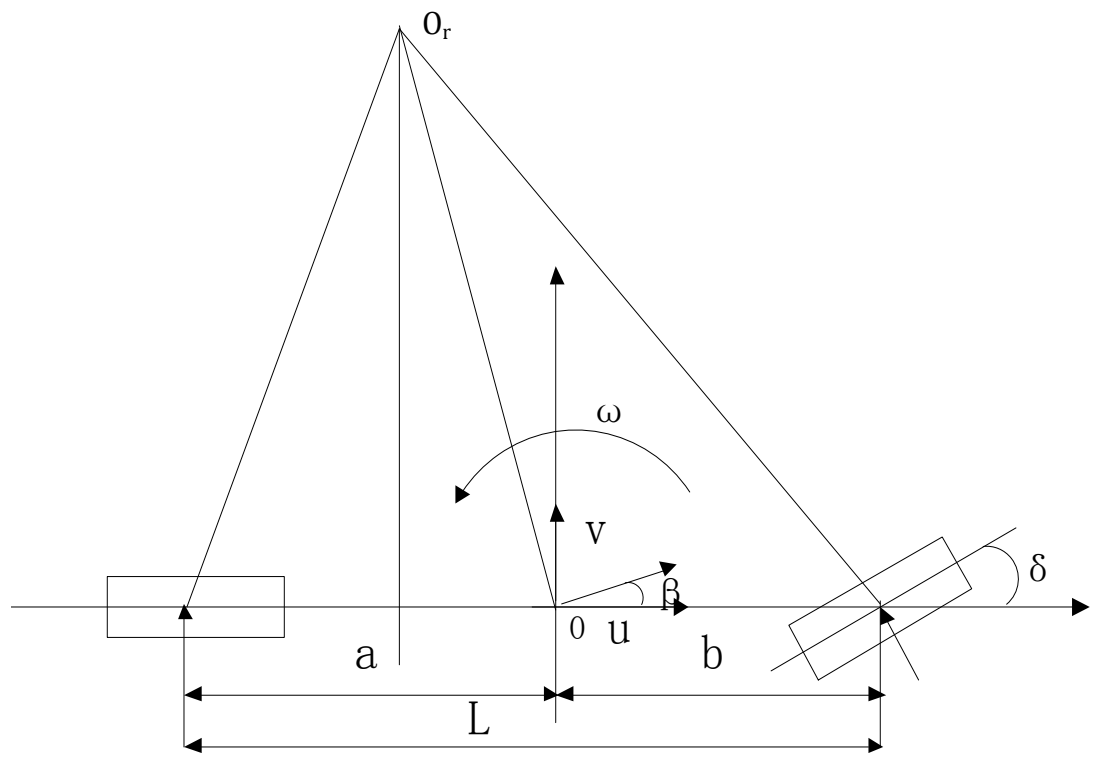

Figure 3. 2-DOF vehicle model. 


$$
\left[\begin{array}{c}
\dot{\beta} \\
\dot{\omega}
\end{array}\right]=\left[\begin{array}{cc}
\frac{C_{1}+C_{2}}{m u} & -1+\frac{a C_{1}-b C_{2}}{m u^{2}} \\
\frac{a C_{1}-b C_{2}}{I_{Z}} & \frac{a^{2} C_{1}+b^{2} C_{2}}{I_{Z} u}
\end{array}\right]\left[\begin{array}{l}
\beta \\
\omega
\end{array}\right]+\left[\begin{array}{c}
-\frac{C_{1}}{m u} \\
-\frac{a C_{1}}{I_{Z}}
\end{array}\right]
$$

The approximate ideal yaw rate can be expressed by Equation (4):

$$
\omega_{1}=\frac{u \delta}{L\left(1+K u^{2}\right)}
$$

where $\omega_{1}$ is approximate ideal yaw rate; $L$ is wheelbase; $K$ is stability coefficient, $K=\frac{m}{L^{2}}\left(\frac{a}{C_{2}}-\frac{b}{C_{1}}\right)$.

However, under the ground attachment limit, the lateral acceleration $a_{y}$ of the vehicle is affected by the formula (5):

$$
\left|a_{y}\right| \leq \mu \cdot g
$$

where $\mu$ is adhesion coefficient; $g$ is gravitational acceleration.

When the sideslip angle is small, ignore the influence of the side angle, $a_{y}$ can be expressed by (6):

$$
a_{y} \approx \omega \cdot u
$$

Combining Equations (5) and (6), it can be corrected to the ideal yaw rate $\omega_{d}:$

$$
\left|\omega_{d}\right|=\min \left\{\left|\omega_{1}\right|,\left|\frac{\mu \cdot g}{u}\right|\right\}
$$

The yaw moment controller uses the PID control method to track the yaw rate and find the additional yaw moment required to maintain the vehicle's handling stability. The difference between the actual yaw rate $\omega$ and the ideal yaw rate $\omega_{d}$ is defined as $e(t)$ :

$$
e(t)=\omega-\omega_{d}
$$

According to the PID control of the mathematical model can be obtained additional yaw moment $\Delta M$ :

$$
\Delta M=N_{p}\left[e(t)+N_{i} \int_{0}^{t} e(t) \mathrm{d} t+N_{d} \frac{\mathrm{d} e(t)}{\mathrm{d} t}\right]
$$

where $N_{p}$ is the scale factor; $N_{i}$ is the integral time constant; $N_{d}$ is the differential time constant.

\subsection{Torque Distributor}

The role of the torque distributor is reasonably generalized force assigned to an actuator. For 4IWD electric vehicles, the force of each actuator refers to the wheel motor/brake applied to the tire on the longitudinal force.

1) First stage: torque distribution

Taking the left-turn condition as an example, the actual yaw moment $M$ of the vehicle and the additional yaw moment required $\Delta M_{1}$ for the first stage can 
be expressed as:

$$
\begin{gathered}
M=\left(F_{x r f}+F_{x r r}-F_{x l f}-F_{x l r}\right) \cdot \frac{B}{2} \\
\Delta M_{1}=\Delta M-M
\end{gathered}
$$

where $F_{x l f}, F_{x r f}, F_{x l r}$ and $F_{x r r}$ are longitudinal force for the left front wheel, right front wheel, left rear wheel, right rear wheel. $B$ is the distance between the wheels.

As the vehicle in the uniform phase, the torque on each wheel is the same, then $F_{x r f}=F_{x r r}$. This stage does not control the inner wheels, and ultimately the longitudinal force on each wheel and the required torque:

$$
\begin{gathered}
T_{x r f}=T_{x r r}=\frac{1}{4} T_{Z}-\frac{1}{2} \Delta M \\
T_{x r f}=T_{x l r}=\frac{1}{4} T_{Z}
\end{gathered}
$$

where $T_{x l f}, T_{x r f}, T_{x l r}$ and $T_{x r r}$ are the torque for left front wheel, the right front wheel, the left rear wheel, the right rear wheel.

2) Torque distribution second stage

In the first stage, when the outside wheels torque is reduced to 0 , it is possible to provide the maximum additional yaw moment for the stage $\Delta M_{1 \max }$ :

$$
\Delta M_{1 \max }=\left(F_{x l f}+F_{x l r}\right) \cdot \frac{B}{2}
$$

However, due to the actual yaw rate being too large, $\Delta M_{1 \max }$ cannot meet the stability requirements. Then the second stage increases the torque of inner wheels and brakes outside wheels. The second stage requires yaw moment $\Delta M_{2}$ :

$$
\Delta M_{2}=\Delta M-\Delta M_{1 \max }
$$

The main consideration of this stage is the torque on the inner wheel and the outer wheel braking torque distribution. The expression for the objective function is:

$$
J=D_{l f} \frac{F_{x l f}^{2}}{\left(\mu F_{z l f}\right)}+D_{l r} \frac{F_{x l r}^{2}}{\left(\mu F_{z l r}\right)}+D_{r f} \frac{F_{x r f}^{2}}{\left(\mu F_{z r f}\right)}+D_{r r} \frac{F_{x r r}^{2}}{\left(\mu F_{z r r}\right)}
$$

where $F_{z l f}, F_{z r f}, F_{z l r}$ and $F_{z r r}$ are the vertical load on each wheel, $D_{i}$ is weight coefficient; $D_{l f}=D_{r f}=1, D_{l f}=D_{r f}=1$.

In the process of optimizing the distribution, the longitudinal force and yaw moment required for the vehicle are as follows:

$$
\left\{\begin{array}{l}
F_{X}=F_{x l f}+F_{x l r}-F_{b r f}-F_{b r r} \\
\Delta M=\frac{B}{2}\left(F_{x l f}+F_{x l r}+F_{b r f}+F_{b r r}\right)
\end{array}\right.
$$

where $F_{b r f}, F_{b r r}$ are brake forces on right front wheel and right rear wheel; $F_{X}$ is the force along the $X$ axis.

The limits of the motor torque and ground adhesion to the wheels are as follows: 


$$
\begin{gathered}
F_{x l f} \leq \min \left(\frac{T_{\max }}{R}, \mu F_{x l f}\right), F_{x l r} \leq \min \left(\frac{T_{\max }}{R}, \mu F_{x l r}\right) \\
F_{b r f} \leq \mu F_{z r f}, F_{b r r} \leq \mu F_{z r r}
\end{gathered}
$$

where $T_{\max }$ is motor peak torque; $R$ is Rolling radius.

Substituting Equation (17) into the optimal objective function formula (16):

$$
\begin{aligned}
J= & D_{l f} \frac{\left[\frac{1}{2}\left(\frac{2 \Delta M_{2}}{B}+F_{X}\right)-F_{x l r}\right]^{2}}{\left(\mu F_{z l f}\right)^{2}}+D_{l r} \frac{F_{x l r}^{2}}{\left(\mu F_{z l r}\right)^{2}} \\
& +D_{r f} \frac{\left[\frac{1}{2}\left(\frac{2 \Delta M_{2}}{B}+F_{X}\right)-F_{b r r}\right]^{2}}{\left(\mu F_{z r f}\right)^{2}}+D_{r r} \frac{F_{x r r}^{2}}{\left(\mu F_{z r r}\right)^{2}}
\end{aligned}
$$

The new objective function (20) is used to derive the $F_{x l r}$ and $F_{b r r}$ :

$$
\begin{aligned}
& \frac{\partial J}{\partial F_{x l r}}=D_{l r} \frac{2 F_{x l r}}{\left(\mu F_{z l r}\right)^{2}}-D_{l f} \frac{\left[\frac{1}{2}\left(\frac{2 \Delta M_{2}}{B}+F_{X}\right)-F_{x l r}\right]^{2}}{\left(\mu F_{z l f}\right)^{2}}=0 \\
& \frac{\partial J}{\partial F_{b r r}}=D_{r r} \frac{2 F_{x r r}}{\left(\mu F_{z r r}\right)^{2}}-D_{l f} \frac{\left[\frac{1}{2}\left(\frac{2 \Delta M_{2}}{B}+F_{X}\right)-F_{b r r}\right]^{2}}{\left(\mu F_{z r f}\right)^{2}}=0
\end{aligned}
$$

Under the constraints of (21) and (22), the final solution is:

$$
\begin{gathered}
F_{x l r}=\frac{\left(\frac{2 \Delta M_{2}}{B}+F_{X}\right)\left(\mu F_{z l r}\right)^{2}}{\left[4\left(\mu F_{z l f}\right)^{2}+2\left(\mu F_{z l r}\right)^{2}\right]} \\
F_{b r r}=\frac{\left(\frac{2 \Delta M_{2}}{B}+F_{X}\right)\left(\mu F_{z r r}\right)^{2}}{\left[4\left(\mu F_{z r f}\right)^{2}+2\left(\mu F_{z r r}\right)^{2}\right]}
\end{gathered}
$$

According to Equations (17), (23), and (24), the torque of the second stage can be calculated as:

$$
\begin{gathered}
T_{x l f}=\frac{1}{4} T_{Z}+\left[\frac{1}{2}\left(\frac{2 \Delta M_{2}}{B}+F_{X}\right)-F_{x l r}\right] R \\
T_{x l r}=\frac{1}{4} T_{Z}+F_{x l r} R \\
T_{b r f}=\left[\frac{1}{2}\left(\frac{2 \Delta M_{2}}{B}-F_{X}\right)-F_{b r f}\right] R \\
T_{b r r}=F_{b r r} R
\end{gathered}
$$

\section{Simulation and Analysis}

This paper used Carsim and MATLAB/SIMULINK platform to build a vehicle 
dynamics model, a double lane change model, and a slalom model. The simulation includes double lane change maneuver and Slalom maneuver. The parameters of the simulation vehicle are shown in the following Table 1.

\subsection{Double Lane Change Maneuver}

To simulate the extreme driving conditions, we take the road friction coefficient of 0.2 , equivalent to compaction of the snow road. The simulation is based on the comparison between without control and torque control. The simulation results are shown in Figures 4-8.

\subsection{Slalom Maneuver}

Simulation vehicle in situ start, accelerated to $80 \mathrm{~km} / \mathrm{h}$ and road friction coefficient is 0.8. The simulation results are shown in Figures 9-13.

Figure 5 and Figure 10 show the speed curve, in the absence of control, the

Table 1. Geometric parameters of simulation vehicle.

\begin{tabular}{cc} 
Parameters & Value \\
Vehicle mass $(\mathrm{m} / \mathrm{kg})$ & 1111 \\
Body rotational inertia about the $X$ axis $I_{X} /\left(\mathrm{kg} \cdot \mathrm{m}^{2}\right)$ & 288.0 \\
Body rotational inertia about the $Y$ axis $I_{Y} /\left(\mathrm{kg} \cdot \mathrm{m}^{2}\right)$ & 2031.4 \\
Body rotational inertia about the $Z$ axis $I_{Z} /\left(\mathrm{kg} \cdot \mathrm{m}^{2}\right)$ & 2031.4 \\
Distance between the front axle and centroid $(\mathrm{a} / \mathrm{m})$ & 1.040 \\
Distance between the rear axle and centroid $(\mathrm{b} / \mathrm{m})$ & 1.560 \\
Centroid height $\left(h_{g} / \mathrm{m}\right)$ & 0.540 \\
Front wheel base $(B f / \mathrm{m})$ & 1.481 \\
Rear wheel base $\left(B_{r} / \mathrm{m}\right)$ & 1.481 \\
wheel rolling radius $(R / \mathrm{m})$ & 0.311 \\
Motor peak torque $(30 \mathrm{~s}) /(\mathrm{N} \cdot \mathrm{m})$ & 500 \\
\hline
\end{tabular}

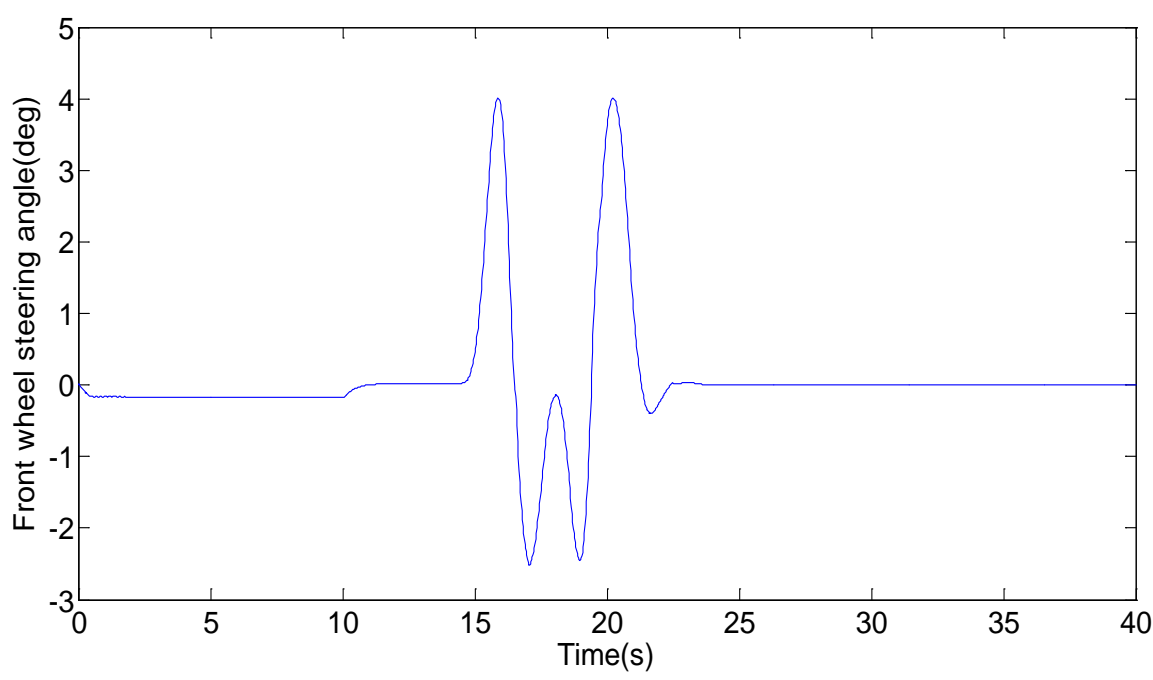

Figure 4. Front wheel steering angle. 


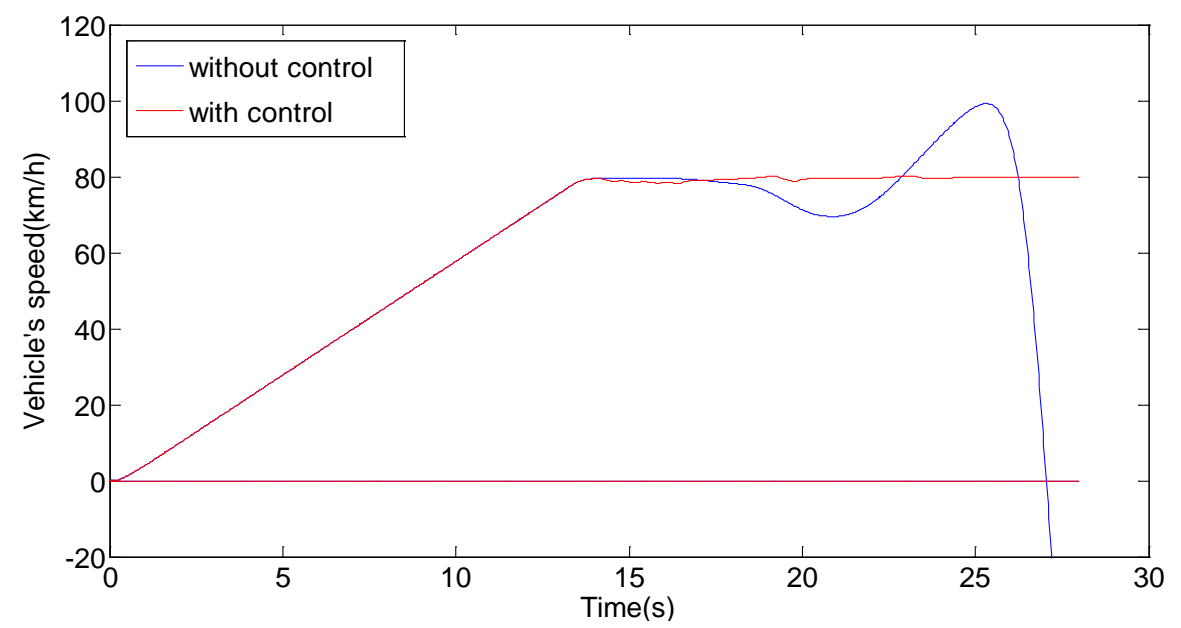

Figure 5. Curves of vehicle's speed.

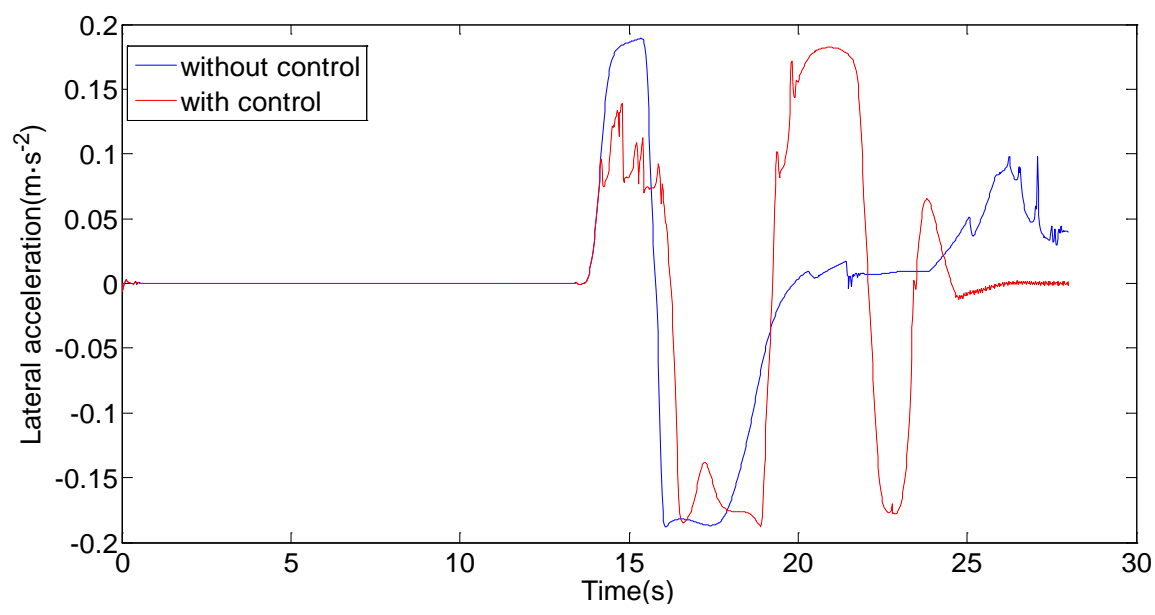

Figure 6. Curves of lateral acceleration.

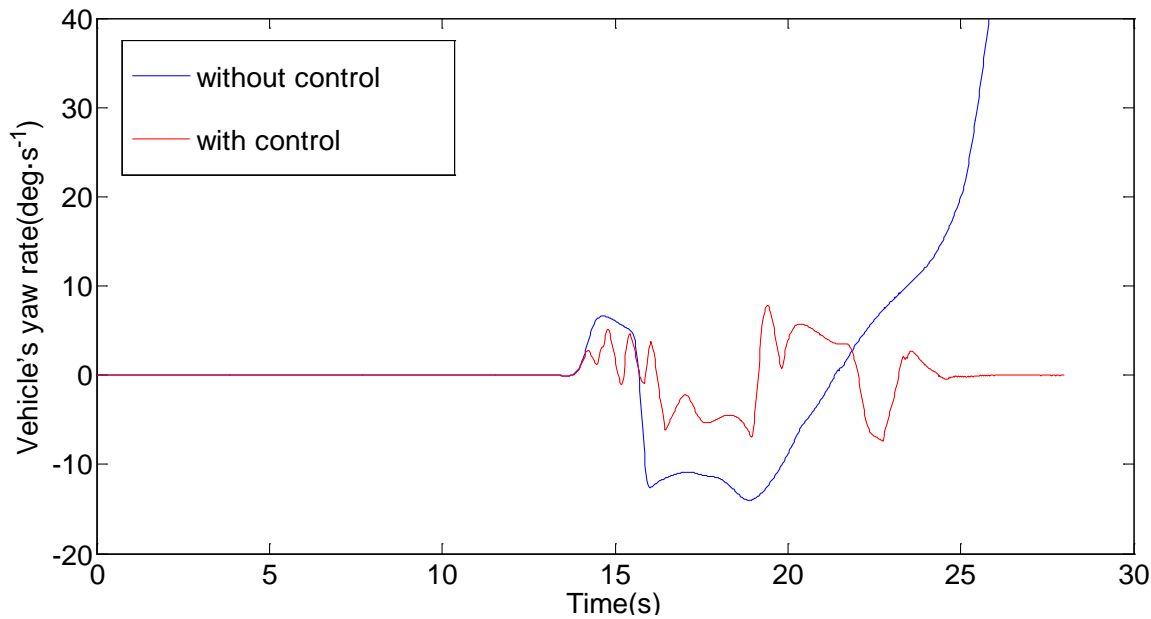

Figure 7. Curves of vehicle's yaw rate.

speed curve changes greatly from the original straight line instability for the lateral sliding. With torque control, the speed fluctuates slightly, but only fluctuates in a very small range. From Figure 6 and Figure 11, the lateral acceleration 


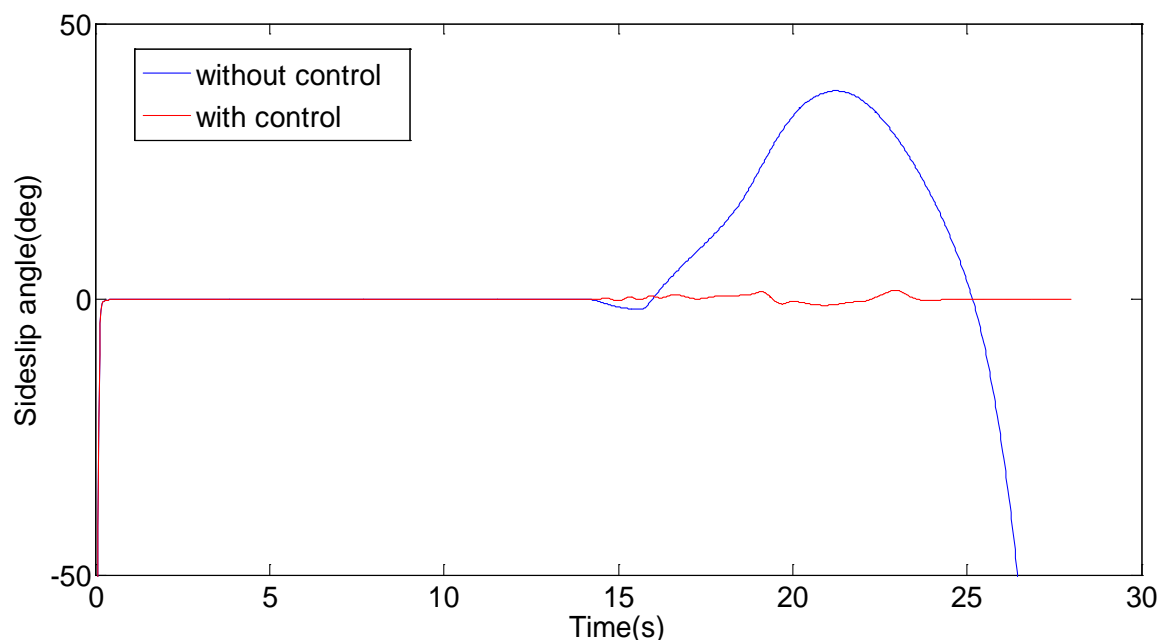

Figure 8. Curves of sideslip angle.

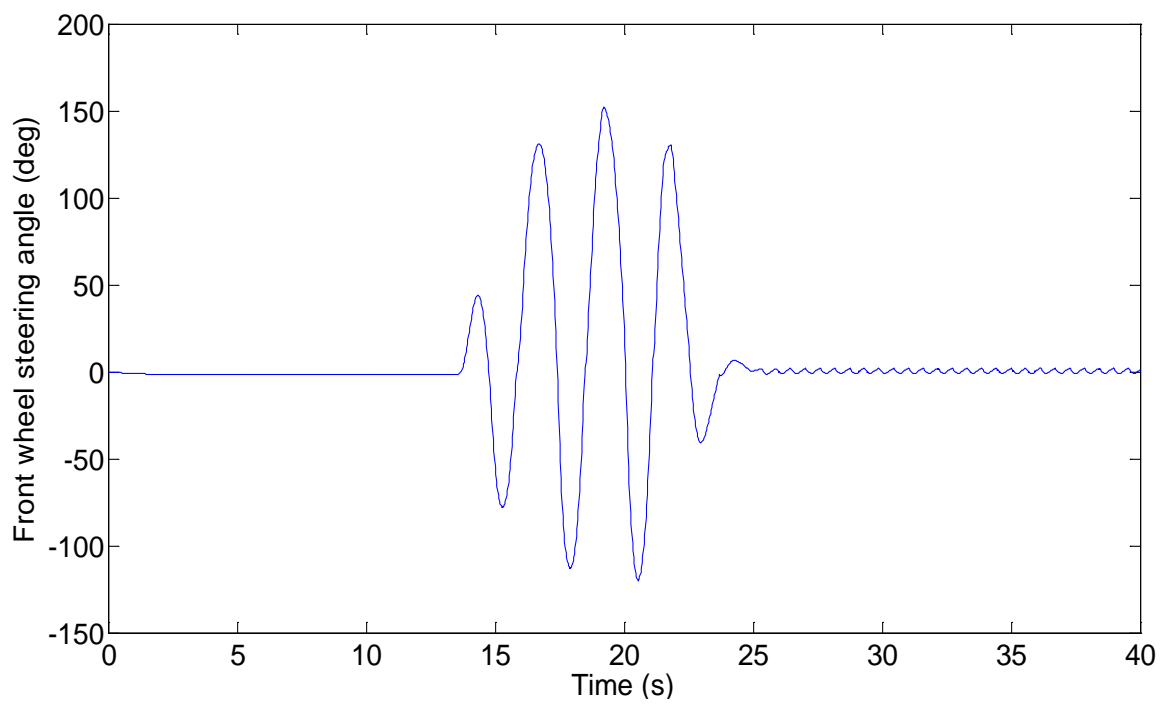

Figure 9. Front wheel steering angle.

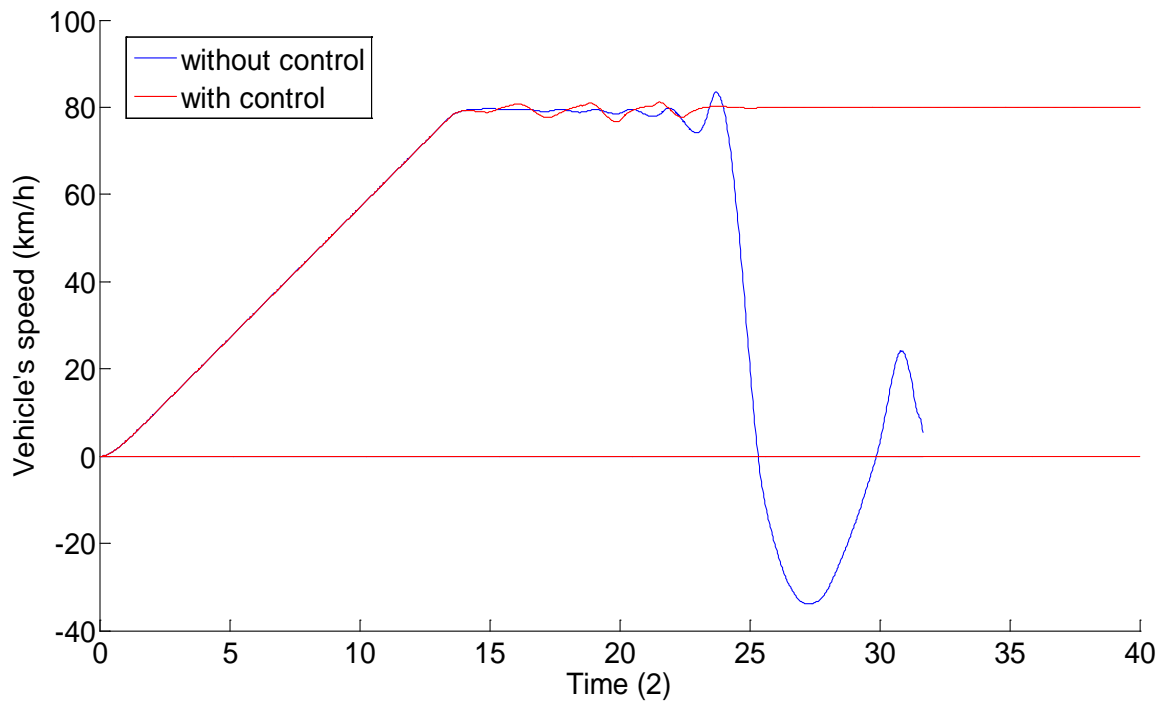

Figure 10. Curves of vehicle's speed. 


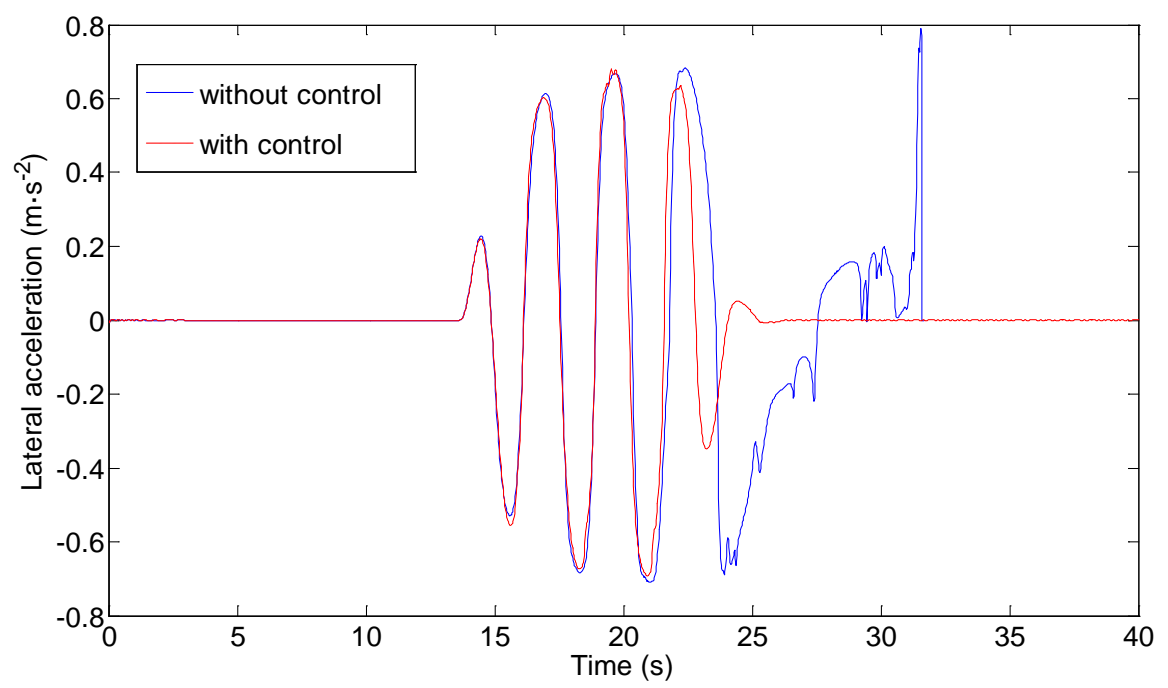

Figure 11. Curves of lateral acceleration.

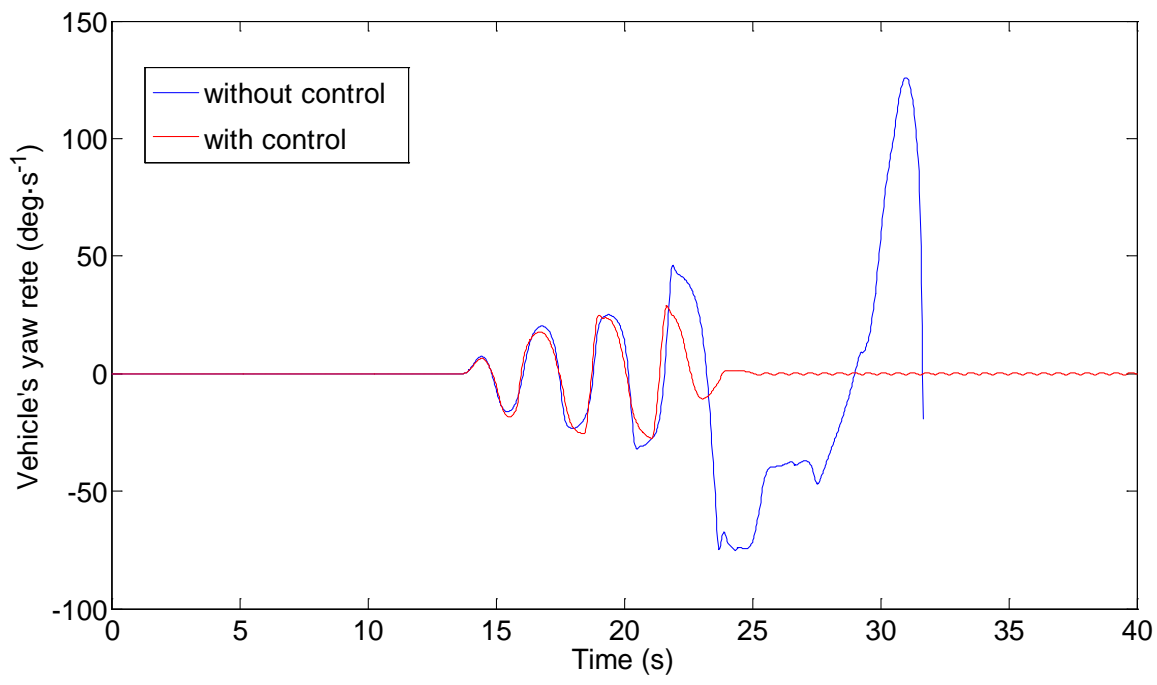

Figure 12. Curves of vehicle's yaw rate.

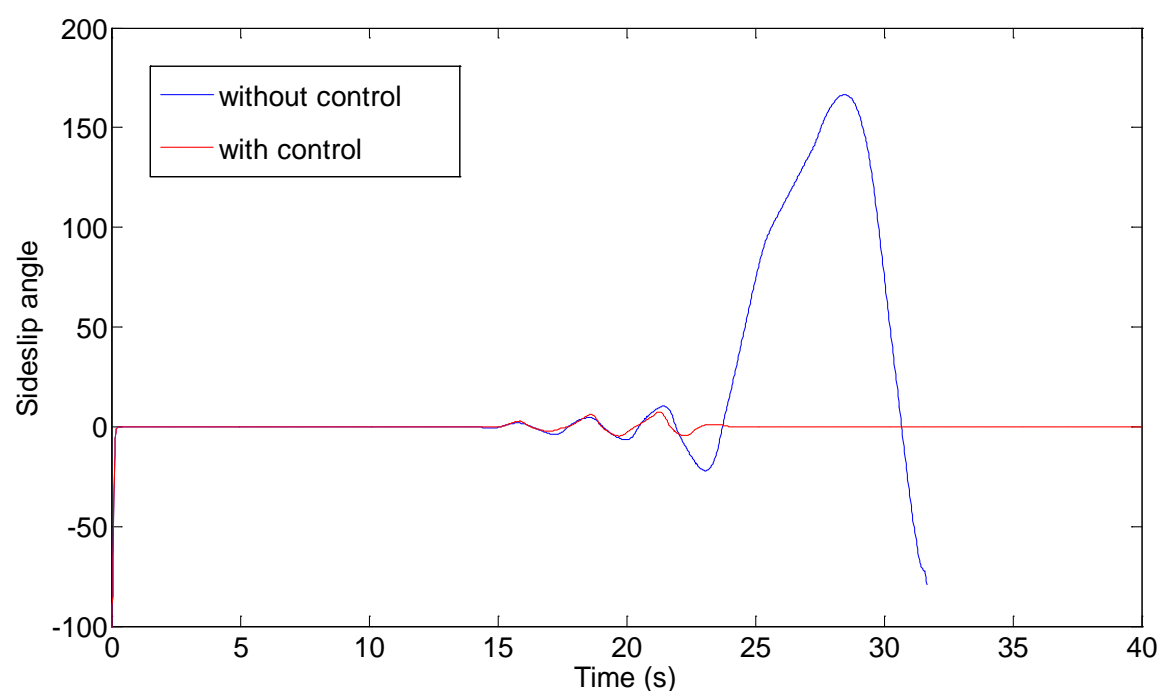

Figure 13. Curves of sideslip angle. 
curve shows that the vehicle has slipped and lost the ability to return to the normal route. With control, the situation is noticeably improved and can be returned to the normal route and the lateral acceleration which is maintained near $0\left(\mathrm{~m} / \mathrm{s}^{2}\right)$. Figure 7 and Figure 12 show that if vehicle is out of control, the yaw rate increased rapidly with instability. In the case of control, the yaw rate is fluctuating within the range of $10(\mathrm{deg} / \mathrm{s})$ and tends to zero after the end of the lane to keep the vehicle stable. Figure 8 and Figure 13 show that the torque distribution control can effectively control the size of the sideslip angle, so that it is always in the vicinity of $0\left(^{\circ}\right)$.

\section{Conclusions}

This paper has presented a control strategy to improve stability applied to a 2 -DOF vehicle model. The first conclusion is that lateral acceleration, yaw rate and sideslip angle are important parameters of vehicle stability. If the value of these parameters is too large, the vehicle will be unstable.

The second conclusion is that the presented control strategy can make lateral acceleration, yaw rate and sideslip angle within a reasonable range by controlling the torque of each wheel to improve stability.

\section{Acknowledgements}

The authors are grateful to Professor Zhang Huanhuan of this research. She gives me many advices about theoretical knowledge and simulation.

\section{References}

[1] Sakai, S.I. and Hori, Y.C. (2001) Advanced Motion Control of Electric Vehicle with Fast Minor Feedback Loops: Basic Experiments Using the 4-Wheel Motored EV "UOT Electric March II". The Society of Automotive Engineers of Japan, 22, 527 p.

[2] Qing, G., Zou, J. and Xu, J., et al. (2014) Torque Allocation Strategy of 4WID In-Wheel Motor Electric Vehicle Based on Objective Optimization. Proceedings of the American Control Conference, Institute of Electrical and Electronics Engineers Inc., Portland, 2600-2605.

[3] Massimo, C., Lorenzo, F. and Antonella, F. (2008) Vehicle Yaw Control via Second-Order Sliding-Mode Technique. IEEE Transactions on Industrial Electronics, 55, 3908-3916. https://doi.org/10.1109/TIE.2008.2003200

[4] Yang, B., Chen, N. and Tian, J., et al. (2013) Simulation Research of 4WS Vehicle Handing Stability Based on Proportional Control. Transactions of Beijing Institute of Technology, Beijing, 820-823.

[5] Makoto, K. and Kevin, W. (2006) A Research of Direct Yaw-Moment Control on Slippery Road for In-Wheel Motor Vehicle. Electric Vehicle Symposium \& Exhibition, 2, 122-133.

[6] Jeongmin, K. and Hyunsoo, K. (2007) Electric Vehicle Yaw Rate Control Using Independent In-Wheel Motor. Proceedings of Power Conversion Conference, Nagoya, 705-710.

[7] Zhu, S.Z., Jiang, W. and Yu, Z.P., et al. (2008) Stability Control of Four In-Wheel-Motor Drive Electric Vehicle by Control Allocation. Journal of System Simulation, 18, 4840-4843. 
[8] Yu, Z.P., Jin, W. and Zhang, L.G. (2008) Torque Distribution Control for 4-W heel-Mot or Driving Electric Vehicle. Journal of Tongji University: Natural Science, 38, $1115 \mathrm{p}$.

[9] Ding, X.Y., Zhang, Q.S., Qin, Y.L., et al. (2011) Yaw Stability Control of EV Based on Torque Distribution. High Power Converter Technology, 5, 41-44.

[10] Miao, L.X. (2010) Research on Drive Control Strategy of Four-Wheel Independent Driven Electric Vehicle. Wuhan University of Technology, Wuhan, 49-56.

[11] Pei, J.H. (2005) Research on Vehicle Electronic Stability Program Control System. Chongqing University, Chongqing, 51-60.

[12] Tang, Y.P. (2009) The Research of Electrionic Stability Program Control Based on Direct Yaw Moment Control. Chang'an University, Xi'an, 53-65.

[13] Kang, J. and Yi, K. (2015) Control Allocation Based Optimal Torque Vectoring for 4WD Electric Vehicle. http://papers.sae.org/2012-01-0246/

[14] Yang, W.F. (2010) Automobile Theory. South China University of Technology Press, Guangzhou, 121-144.

Submit or recommend next manuscript to SCIRP and we will provide best service for you:

Accepting pre-submission inquiries through Email, Facebook, LinkedIn, Twitter, etc. A wide selection of journals (inclusive of 9 subjects, more than 200 journals) Providing 24-hour high-quality service User-friendly online submission system Fair and swift peer-review system Efficient typesetting and proofreading procedure Display of the result of downloads and visits, as well as the number of cited articles Maximum dissemination of your research work

Submit your manuscript at: http://papersubmission.scirp.org/

Or contact eng@scirp.org 